\title{
Sara London
}

\section{Love of Line: Notes for an Apprentice Shingler}

The injuries are small ones, the blade slips from the cedar slat to the kneeling knee, or the plane slides off the shingle's edge and shaves the thumb knuckle. Splinters are surprisingly rare, but when the hands are cold, the hammer glances the galvanized nail and slams the horny one, pinching and blistering the pellicle. This is the worst.

What we labor over, a swayback beach house, rests on a rheumatic wharf, our task to pluck the worn wood scales, add new bridgework, a shield of George Washington teeth, clamped against adversity.

We begin with the shingle iron slipping it along the virgin backside of loose dentures, and pull so shakes fly off in our faces, crack and splinter, the sharp dry notes narrating 
fifteen-plus years of weather.

Like dog years, this is ancient

beyond thinning and brittleness.

Where we find rot, we chisel out

the grainy porridge and fill

the gap with new pine,

thick wedges for warmth.

Wood chips in our eyes

make us cry a little,

but mostly we keep right on

through the small disasters

to batten down before nightfall,

our eye on the suture-

horizon stitching low

grey sky to our dark Atlantic.

Tar paper (or a new slick

synthetic stock that doesn't rip

and bears a name too New Age

for song) is whack-stapled

to weary ship-salvage boards,

top layer always over bottom

to keep rain water from seeping

back to wood. Then the sweet

new cedar shields we extract

from fresh bundles and fit, side flush to side

and hammer in twice, milk

oozing from flat four-penny

heads, the soft white fur of mold, like premature infant

fuzz, rising from wet wood

into the crisp autumn

turn of air. 
Chalk lines are best

when workers hold each end, one reaching to the center

to snap, the blue powder

mapping a million points

along a line so straight

the day's doubts are deleted

in its sure direction.

But a course of shingles

followed by another and another parading up the house-these hands saluting, soles of tree, puerile soldiers sweet

as puberty, pressed side to side

so no one stands taller,

though some are fatter,

"hippos," and some are "weasel"-

thin, their bodies set

like brickwork so no two seams

meet-all the bathos of the week

is buried here. Lines

link lines to what we love

in these long hours, the wood

wine of it, the weighted plunge

and smack of hammer and nail,

the hard grip, hammer handle

to palm, the knock, knock, knock

answering back from neighboring

houses and street, wood and nail

and wood, even the smeared blood

marking the rough facade.

We swing and drum the day.

And when we finish, the lines, stacks of horizons, paths to an exacting place, meeting at trim and window, foundation and roof, 
are what we've made. Lines

where cold, rain, wind,

sleet, sun and snow end. Lines

we step across the street

to judge, and when they're fine they're fine, and when they fail they haunt. Order is easy to

plan for, hard to achieve. This is what houses are aboutplanes that meet along degrees we trust. Lines that say,

The weather is up to you.

We unfasten our nail aprons as the sun sends its light into Africa's day. Toss into the toolbox tape measure, plane and knife, hammer, chalkline and coping saw, and head home to husband, or girlfriend or dog, or house, house, bless it, though it doesn't save us from ourselves. And when we sleep, it is the sleep of lines well made, or lines that are not well, marginally mis-measured, but in our dreams slanting earthward or rising toward some inevitable convergence, the confusion of infinite touch, and so we return like some floating angel to the house and remove by glance alone, five fresh courses to correct our quarter-inch mistake. 
When we wake, the error

dissolves into morning,

compulsion keeling into

the undefined plane of day

and its incorrigible knots.

In a year the high wheat

of the wood will fade to blue-grey,

the seams will open a crack,

for the wood has dried and shrunk.

The smell, once fecund as forests, will be salted, and somewhere else

staging will be assembled, a house

be stripped, a dog amused

at what trouble humans go to,

dangling their booted feet

at the face of a house

as the hammers hound the quiet

of day, as the afternoon arcs

around our deep imperfections,

and we measure with expectation

another course, another line. 